\title{
Strategies for time of culling in control of paratuberculosis in dairy herds
}

\author{
A. B. Kudahl, ${ }^{* 1}$ S. S. Nielsen, $†$ and S. Østergaard ${ }^{*}$ \\ ${ }^{*}$ Faculty of Agricultural Sciences, Department of Animal Health and Bioscience, University of Aarhus, Blichers Alle 20, PO Box 50, DK-8830 Tjele, \\ Denmark \\ †Faculty of Life Sciences, Department of Large Animal Sciences, University of Copenhagen, Grønnegårdsvej 8, DK-1870 Frederiksberg, \\ Denmark
}

\begin{abstract}
Effect of time for culling cows infected with Mycobacterium avium ssp. paratuberculosis on prevalence and profitability was identified through simulations. Seven test-and-cull strategies with different culling criteria and no attempts to close infection routes were compared with strategies with (1) no control and (2) closure of infection routes and no culling. The effects on true prevalence and gross margin were evaluated in a herd with typical reproduction management (heat detection rate of $38 \%$ ). This was repeated in a herd with poor reproduction management (heat detection rate of $28 \%$ ), because poor reproduction leads to lack of replacement animals, which was hypothesized to affect the economic effects of culling. Effects of varying prices of milk, replacement heifers, and hourly wages were also evaluated. The simulated results predicted that immediate culling after the first positive antibody ELISA test would be the most effective culling strategy to reduce prevalence. However, closing transmission routes was even more effective in reducing the prevalence. In the first 3 to $6 \mathrm{yr}$, all test-and-cull strategies reduced gross margin by US $\$ 5$ to $55 /$ stall per year. These losses were fully compensated by increased gross margin in yr 6 to 19. In the short run (7 yr with typical reproduction and $10 \mathrm{yr}$ with poor reproduction), it was most profitable to cull test-positive cows when their milk yield decreased below $85 \%$ of that expected according to their parity and lactation stage, especially in herds with poor reproduction management. However, this strategy only stabilized the prevalence and did not reduce it. In the long term ( $>7 \mathrm{yr}$ from implementation of a strategy), it was most profitable to cull cows immediately or as soon as possible after testing positive the first time. Varying milk prices did not affect the ranking between the different culling strategies. Increased market price $(20 \%)$ of replacement heifers made all culling strategies less profitable and made culling based on a
\end{abstract}

Received October 15, 2010.

Accepted April 8, 2011.

${ }^{1}$ Corresponding author: Anneb.Kudahl@agrsci.dk milk yield criterion the most profitable culling strategy for a longer period (11 to $13 \mathrm{yr}$ ). A $20 \%$ reduction in heifer price made immediate culling after a positive test the most profitable strategy overall in herds with typical reproduction, and after $9 \mathrm{yr}$ in herd with poor reproduction. To conclude, the ideal culling strategy depends on the aim of intervention, the time horizon, and the reproductive capabilities combined with prices of replacement animals.

Key words: culling strategy, economy, paratuberculosis, prevalence reduction

\section{INTRODUCTION}

Paratuberculosis (PTB) is caused by infection with Mycobacterium avium ssp. paratuberculosis (MAP), which can lead to chronic enteritis, decreased milk production, devastating diarrhea, and death (Chiodini et al., 1984). The disease thus results in reduced animal welfare and economic losses on affected farms and is highly prevalent in dairy herds (Kennedy et al., 2001; Nielsen and Toft, 2009). Calves, especially newborn calves, are considered most susceptible to infection. They are infected through oral uptake of MAP shed in colostrum, milk, or feces from adult cattle, and at an age of around $1 \mathrm{yr}$, they may be almost resistant (Chiodini et al., 1984). Transmission routes are closed by ensuring that calves never come into contact with contaminated material or infectious cows, as follows: colostrum and milk are provided from test-negative cows only, good hygiene is maintained in the calving area and calf barn, calves are immediately separated from dams, and calves are reared separately from adult cattle (Kennedy et al., 2001). The potential of MAP as a zoonotic agent (Behr and Kapur, 2008) and the economic losses to farmers (Ott et al., 1999) motivate both the dairy industry and farmers to take initiatives to reduce the prevalence of MAP infections in the herds and thereby the occurrence of MAP in retail milk and meat. To date, no effective and economically favorable treatments are available. Control of infection therefore requires the closure of transmission routes and removal of infectious animals. Several major dairy- 
producing countries (e.g., the United States, Australia, the Netherlands, and Denmark) have initiated different types of voluntary programs to control MAP infections in herds (Kennedy and Nielsen, 2007). Earlier simulations (Groenendaal et al., 2002; Kudahl et al., 2007) illustrated that closing transmission routes is the most effective means to decrease the prevalence of MAP infections in the herd. In practice, however, many farmers find it difficult and time consuming to stop transmission effectively. Therefore, they rely more on culling strategies, which raises the question of the most optimal time for culling the infected animals. Simulation studies by $\mathrm{Lu}$ et al. (2010) suggested that testbased culling interventions alone reduce the prevalence of MAP at a very slow rate, and that combining culling with reduction of transmission through improved management might be more effective than either approach alone. Kudahl et al. (2008) predicted that as long as some transmission routes are more or less open, prompt culling of infectious animals is important, whereas if transmission routes are closed properly, prompt culling is less important. Lu et al. (2008) supported these results by finding that with proper herd management to reduce transmission, culling of only high-shedding animals may be effective. However, on farms with poor management, culling of both high- and low-shedding animals will be necessary. The studies by $\mathrm{Lu}$ et al. (2008, 2010) did not evaluate economic effects. Culling of low-shedding animals would, however, imply premature culling, which can be very costly, especially in case of high milk yield of test-positive cows (Smith et al., 2009), other major disease problems in the herd, or reproduction-related problems leading to a lack of replacement animals. Culling these animals too late will increase the risk of transmission of MAP to calves in the herd, and can be costly as well. Therefore, farmers often seek the economically optimal time for culling of a MAP test-positive cow. A short-term economically favorable strategy might be inefficient in reducing herd prevalence and thereby be costly in the long term. Furthermore, the answer may depend on current prices (of milk, feed, and other items), reproductive strategy, and other herd-specific conditions. Decisions on which cows in a herd to replace, and when, are complex because they depend on animal welfare (serious diseases, irreparably injured animals) and economic (low milk yield, fertility problems) factors (Fetrow et al., 2006). The question is thus too complex to answer by empirical data, whereas simulation studies facilitate analyses of both short- and long-term effects on production and economy in these "what-if" scenarios. Therefore, this study aimed to determine the optimal time for culling ELISA-positive cattle by simulations under conditions where no other specific action is taken to close transmission routes for MAP in the herd.

The work presented here includes the results of a simulation study, in which short- and long-term effects of 7 test-based culling strategies on herd prevalence, production, and herd economy are evaluated in herds with 2 levels of reproduction management and with varying price sets for milk, replacement heifers, and hourly wages. The culling strategies are compared with a "no control" scenario and an "improved management" scenario with $80 \%$ closure of transmission routes.

\section{MATERIALS AND METHODS}

Simulations were performed using the dairy herd simulation model PTB-Simherd of Kudahl et al. (2007), which is based on Simherd, a dynamic stochastic and mechanistic Monte Carlo simulation model simulating a dairy herd including young stock (Østergaard et al., 2003, 2005). Every animal is described by weekly updated parameters describing age, parity, lactation stage, milk yield potential, current milk yield, reproduction status, status of several diseases including true status of PTB infection, and latest test responses of milk antibody ELISA test and fecal culture. In the model, an animal can have 5 MAP-infection stages: susceptible, latently infected, low shedding, high shedding, and clinically affected. In the presented scenarios, the milk ELISA test was evaluated and the relationship between the ELISA test response and the true infection stage or shedding intensity of the animal is listed as sensitivity in Table 1 (based on data from Nielsen et al., 2008). Management of the herd is likewise specified by parameters describing, for example, heat detection rate, replacement criteria, feeding, occurrence of diseases, and effects and management of diseases (including paratuberculosis). The PTB-Simherd model has already been used for prediction of the productionrelated and economic effects of different control strategies against MAP infections (Kudahl et al., 2007, 2008). In the PTB-Simherd model, a paratuberculosis module is added to the basic herd dynamics from the Simherd model. All other parts of the Simherd model are kept constant in these simulations.

In the present study, the model was further developed to facilitate the simulation of additional culling strategies to control MAP infections. The assumed sensitivities of the milk ELISA test were updated based on Nielsen (2008) as listed in Table 1. The effects of MAP infection on slaughter weight were updated based on Kudahl and Nielsen (2009). The price-set used for calculation of economic figures was updated to reflect the current Danish price level in April 2010, and the milk 
Table 1. User-specified values for sensitivities and specificities of milk ELISA in cows of first and higher parities used in the dairy herd simulation model PTB-Simherd (Kudahl et al., 2007)

\begin{tabular}{|c|c|c|c|c|c|c|}
\hline \multirow[b]{2}{*}{ Infection state } & \multirow[b]{2}{*}{ Parity } & \multicolumn{4}{|c|}{ Sensitivity $^{1}$} & \multirow[b]{2}{*}{ Specificity $^{2}$} \\
\hline & & $\begin{array}{l}7-105 \\
\text { DIM }\end{array}$ & $\begin{array}{c}106-203 \\
\text { DIM }\end{array}$ & $\begin{array}{c}204-300 \\
\text { DIM }\end{array}$ & $\begin{array}{c}\text { 301-398 } \\
\text { DIM }\end{array}$ & \\
\hline Uninfected & 1 & - & - & - & - & 99 \\
\hline Latent infected & 1 & 10 & 10 & 10 & 10 & - \\
\hline Low shedding & 1 & 50 & 60 & 65 & 70 & - \\
\hline High shedding & 1 & 90 & 90 & 90 & 90 & - \\
\hline Clinically affected & 1 & 90 & 90 & 90 & 90 & - \\
\hline Uninfected & $>1$ & - & - & - & - & 99 \\
\hline Latent infected & $>1$ & 10 & 10 & 10 & 10 & - \\
\hline Low shedding & $>1$ & 60 & 70 & 75 & 75 & - \\
\hline High shedding & $>1$ & 90 & 90 & 90 & 90 & - \\
\hline Clinically affected & $>1$ & 90 & 90 & 90 & 90 & - \\
\hline
\end{tabular}

${ }^{1}$ Sensitivity measures the proportion of actual positives that were correctly identified.

${ }^{2}$ Specificity measures the proportion of negatives that were correctly identified.

price was subsequently varied by $-5 \%$ and $+5 \%$ to test for price sensitivity, because milk price is known to be the most important factor influencing gross margin. In addition, the market price of pregnant replacement heifers was varied (by $20 \%$ and $-20 \%$ ) because this price was expected to have an important effect when evaluating different culling strategies. The price of sold and purchased heifers was expected to be the same (i.e., no intermediary). The price of raising a heifer depended on calving age, but was US $\$ 1,254$, on average, covering costs for feed, insemination, and veterinarian. The market price of a heifer was higher (US\$1,444) and reflected the actual balance between demand and supply. In our scenarios, farmers had an economic benefit from raising their replacement animals. Nine culling strategies were simulated for $20 \mathrm{yr}$ in dairy herds with an initial true PTB prevalence of $25 \%$. All scenarios were simulated with 1,000 repetitions. The economic effects of culling are known to depend on the availability of replacement animals and thus directly on the quality of reproduction management of the farmer and reproductive disorders of the cows (Clausen et al., 1995). Therefore, the culling strategies were simulated in 2 herds, one with an average reproductive performance (heat detection rate of $38 \%$ ) and one herd with poor reproduction management (heat detection rate of $28 \%$ ). In scenarios comprising testing of animals, testing was performed quarterly with a commercial milk antibody ELISA test (ID-Screen, ID-Vet, Montpellier, France) on all lactating cows. The main characteristics of the 2 initial herds are listed in Table 2. Culling based on the last 4 milk ELISA test results was presented in Kudahl et al. (2008), and found not very effective (at best prevalence-stabilizing). That was also the case for culling strategies based on confirmation of positive milk ELISA tests with fecal culture, which was even more ineffective and quite expensive (Kudahl et al., 2007). In the present paper, culling based on just one positive test-result was evaluated by using the following 9 strategies:

1. No control: No testing is performed; typical management and hygiene level (see below) where no attempt is made to reduce transmission of MAP.

2. Culling for welfare reasons only: No testing; clinically diseased cows are culled as soon as they show clinical symptoms of PTB.

3. Cows culled 1 yr after first (ELISA) positive test result.

4. Cows culled 6 mo after first (ELISA) positive test result.

5. Cows culled 3 mo after first (ELISA) positive test result.

6. Test (ELISA)-positive cows are not culled until their daily milk yield decreases below $85 \%$ of what would be expected according to their parity and lactation stage (hereafter called the milk yield criterion). In this way, low producers are culled soon after a positive test and high producers later after a positive test.

7. Test (ELISA)-positive cows move to the top of the culling list and are consequently culled as soon as a heifer is ready to enter the herd. Thereby, other cows on the culling list with other health problems or reproductive disorders or low milk yield are kept in the herd for longer. If more than one positive cow is on the culling list, the lowest-yielding cow is culled first.

8. Test (ELISA)-positive cows are culled immediately.

9. No testing and culling (for MAP infections); very good management is simulated by specifying all 
Table 2. Basic herd characteristics of the 2 initial herd types

\begin{tabular}{lccrrr}
\hline & \multicolumn{2}{c}{ Good reproduction } & & \multicolumn{2}{c}{ Poor reproduction } \\
\cline { 2 - 3 } \cline { 5 - 6 } Item & Mean & \multirow{2}{*}{ SD $^{1}$} & & Mean & SD \\
\hline Herd size (cows) & 197.4 & 1.1 & & 186.6 & 5.8 \\
No. of calves (<1 yr) & 86.6 & 8.0 & & 71.9 & 8.3 \\
No. of heifers (>1 yr) & 83.6 & 7.8 & & 74.0 & 8.0 \\
Annual culling rate (\%) & 41.4 & 3.5 & & 43.1 & 4.0 \\
Milk yield (kg/cow per year) & 9,795 & 132 & & 9,824 & 136 \\
No. of cows milk ELISA positive in last test & 14.2 & 4.2 & & 14.0 & 4.0 \\
True herd prevalence (\%) & 24.5 & 5.5 & & 25.0 & 3.2 \\
True prevalence calves (\%) & 27.8 & 7.0 & & 29.4 & 7.9 \\
True prevalence heifers (\%) & 37.2 & 9.0 & & 35.8 & 10.0 \\
True prevalence cows parity 1 (\%) & 27.0 & 3.9 & & 24.1 & 3.5 \\
True prevalence cows parity 2 (\%) & 23.4 & 4.0 & & 22.4 & 4.1 \\
True prevalence cows parity 3+ (\%) & 18.0 & 3.0 & & 19.1 & 3.5 \\
\hline
\end{tabular}

${ }^{1}$ Standard deviation of the 1,000 initial herds.

MAP transmission risks to be only $20 \%$ of the level of the "no control."

Strategies 3 to 5 and 8 are simulated to evaluate the effect of the lag time from testing positive to culling. They are all practiced by some farmers, and we wanted to evaluate the rationale of these strategies.

Previous simulations indicated that if all transmission routes were closed by improving management, additional testing and culling had almost no effect (Kudahl et al., 2007, 2008). Therefore, in the present study (except strategy 9), management of transmission routes for MAP was specified to represent a situation where no specific action was taken to close transmission routes. Accordingly, it was assumed that a calf and its dam spend $24 \mathrm{~h}$ together, the calf receives colostrum from its own dam and is allowed to suckle, and the hygiene in the calving area and calf barn is at an average level. Risk of transmission through milk is reduced to $15 \%$ of the level from earlier simulations with PTB-Simherd, because this infection risk has been estimated to be lower than previously expected (Nielsen et al., 2008).

General management of the farm was specified to represent a typical Danish dual-purpose dairy herd (milk and beef) with additional young stock. Herd size was set to a minimum of 180 cows and a maximum of 200 , and when a cow is culled or dies she is replaced by a down-calving heifer from the herd. If a heifer is not available and the herd size decreases below 180 cows, a heifer will be purchased. If the entrance of a down-calving heifer will make the herd size exceed 200 cows, then the heifer is sold. In the model, the economic effects of culling are thus simulated directly by the slaughter value of the animal and the difference in production of the slaughtered animal and the replacement animal. In the model, the main effect of MAP infection is reduced milk production. The total economic effects of MAP infection and control in the herd also includes income from slaughtered animals and sold heifers and bull calves, together with costs for feed, purchased heifers, veterinarian, artificial insemination, MAP testing, and additional labor related to improved management (at an hourly wage of US\$22). For a full description of the model, see Kudahl et al. (2007). In strategy 9, extra management related to improved management was assumed to take 50 min ( US\$17.6) per calving when all MAP transmission routes were reduced to $20 \%$ of the original ("no control") level. This management implies all the routines described in the introduction. The hourly wages were varied from $-30 \%$ to $+30 \%$ to reflect variations in wages depending on who is taking care of these tasks (i.e., level of education) and to reflect differences between farms. Future costs and revenues were discounted. The effects of the different strategies are presented as the difference between total effect of that strategy and the total effect of the "no control" strategy.

\section{RESULTS AND DISCUSSION}

Economic results during only the first $10 \mathrm{yr}$ of simulations are presented in Figures 1 to 4 to make it easier to distinguish the curves. This period is also often the most relevant timeframe for farmers and advisors. In the period from yr 10 to 20, the order of the curves did not change and the slopes of the economy curves changed negligibly, whereas the slopes of the prevalence curves approached individual limits (became horizontal). Cumulated economic results after 10 and $20 \mathrm{yr}$ are presented in Tables 3 and 4, together with the year when the initial losses related to the culling strategy were compensated by increased gross margin (breakeven point). The effect on milk yield in yr 5, 10, and 20 are presented in Tables 5 and 6 . Results in Tables 3 
Table 3. In a herd with typical reproduction, the cumulated economic effects of the strategies in yr 5,10 , and 20 are compared with strategy 1 (nothing was done to control paratuberculosis)

\begin{tabular}{|c|c|c|c|c|}
\hline \multirow[b]{2}{*}{ Strategy } & \multicolumn{3}{|c|}{ Cumulated effect $^{1}$ (US $\$ /$ stall per year) } & \multirow{2}{*}{$\begin{array}{c}\text { Year of } \\
\text { break-even }\end{array}$} \\
\hline & Yr 5 & Yr 10 & Yr 20 & \\
\hline 1. No control of $\mathrm{MAP}^{3}$ infections & 0 & 0 & 0 & 0 \\
\hline 2. Culling of only clinically diseased cows & $15(7)$ & $53(10)$ & $158(14)$ & 1 \\
\hline 3. Culling 1 yr after first positive test & $-48(7)$ & $20(10)$ & $291(18)$ & 10 \\
\hline 4. Culling $6 \mathrm{mo}$ after first positive test & $-58(7)$ & $36(11)$ & $457(18)$ & 9 \\
\hline 5. Culling 3 mo after first positive test & $-63(7)$ & $56(11)$ & $633(16)$ & 9 \\
\hline 6 . Test positives culled at yield $<85 \%$ of expected & $-28(7)$ & $128(9)$ & $721(13)$ & 7 \\
\hline 7. On top of culling list when getting test positive & $-109(7)$ & $28(11)$ & $669(16)$ & 10 \\
\hline 8. Immediate culling of test positive cows & $-73(7)$ & $81(11)$ & $766(15)$ & 9 \\
\hline 9. Improved management, no testing & $-80(6)$ & $10(9)$ & $493(13)$ & 10 \\
\hline
\end{tabular}

${ }^{1}$ The economic effects are calculated as the difference in gross margin per cow per year between the individual strategies and the strategy 1 . These differences are cumulated by year until yr 5 , yr 10, and yr 20; standard error of the difference is shown in parentheses.

${ }^{2}$ The year of break-even is the year (after onset of the strategy) where the initial losses are counterbalanced by increased gross margin.

${ }^{3}$ Mycobacterium avium ssp. paratuberculosis.

to 6 are presented as the difference between the means of individual culling strategies and the "no control" strategy. This is to illustrate the effect of doing "something" instead of nothing. When calculating the total milk production or gross margin related to a strategy, the standard deviation was 1 to $3 \%$ of the mean when simulating 1,000 iterations.

\section{Effect on Prevalence}

Faster culling of test-positive cows was predicted to lead to faster reduction of prevalence (Figure 1). The strategy in which nothing is done to control MAP infection (strategy 1) resulted in an increase in the true prevalence from 25 to $70 \%$ during the first $10 \mathrm{yr}$ (Figure 1). Immediate culling after the first positive test of a cow (strategy 8) was the most effective culling strategy. However, replacing test-and-culling strategies with improved management by closing transmission routes $80 \%$ (strategy 9) was the most effective strategy, as previously shown (Groenendaal et al., 2002; Kudahl et al., 2007). All strategies with a prevalence-reducing effect were less effective in doing so in herds with poor reproduction (Figure 2) than in herds with good reproduction (Figure 1). A reduction to $10 \%$ prevalence took $9 \mathrm{yr}$ in a herd with good reproduction and $14 \mathrm{yr}$ in a herd with poor reproduction (not shown).

\section{Effect on Economy}

Culling of only clinically diseased cows (strategy 2) was the most profitable strategy in the first 4 to $6 \mathrm{yr}$,

Table 4. In a herd with poor reproduction, the cumulated economic effects of the strategies in yr 5, 10, and 20 are compared with strategy 1 (nothing was done to control paratuberculosis)

\begin{tabular}{|c|c|c|c|c|}
\hline \multirow[b]{2}{*}{ Strategy } & \multicolumn{3}{|c|}{ Cumulated effect $^{1}$ (US $\$ /$ stall per year) } & \multirow{2}{*}{$\begin{array}{c}\text { Year of } \\
\text { break-even }\end{array}$} \\
\hline & Yr 5 & Yr 10 & Yr 20 & \\
\hline 1. No control of $\mathrm{MAP}^{3}$ infections & 0 & 0 & 0 & 0 \\
\hline 2. Culling of only clinically diseased cows & $6(9)$ & $27(16)$ & $114(20)$ & 1 \\
\hline 3. Culling 1 yr after first positive test & $-103(9)$ & $-166(16)$ & $23(19)$ & 19 \\
\hline 4. Culling $6 \mathrm{mo}$ after first positive test & $-132(9)$ & $-174(16)$ & $116(19)$ & 17 \\
\hline 5. Culling $3 \mathrm{mo}$ after first positive test & $-157(10)$ & $-181(16)$ & $200(20)$ & 16 \\
\hline 6 . Test positives culled at yield $<85 \%$ of expected & $-55(9)$ & $0(16)$ & $403(21)$ & 10 \\
\hline 7. On top of culling list when getting test positive & $-184(10)$ & $-187(16)$ & $167(21)$ & 16 \\
\hline 8. Immediate culling of test positive cows & $-183(10)$ & $-181(16)$ & $293(20)$ & 15 \\
\hline 9. Improved management, no testing & $-67(9)$ & $16(17)$ & $409(21)$ & 10 \\
\hline
\end{tabular}

${ }^{1}$ The economic effects are calculated as the difference in gross margin per cow per year between the individual strategies and the strategy 1 . These differences are cumulated by year until yr 5 , yr 10 , and yr 20 ; standard error of the difference is shown in parentheses.

${ }^{2}$ The year of break-even is the year (after onset of the strategy) where the initial losses are counterbalanced by increased gross margin.

${ }^{3}$ Mycobacterium avium ssp. paratuberculosis. 
Table 5. In a herd with typical reproduction, the effects on milk yield of the 8 control strategies are listed as the milk yield/cow per year (kg of ECM) in strategies 2 to 9 minus that in strategy 1 (standard error of the difference in parentheses)

\begin{tabular}{|c|c|c|c|c|}
\hline Strategy & \multicolumn{3}{|c|}{ Effect on milk yield (kg of ECM/cow per yr) } & $\begin{array}{c}\text { Replacement rate } \\
\text { Yr } 20^{1}(\%)\end{array}$ \\
\hline 1. No control of $\mathrm{MAP}^{2}$ infections & 0 & 0 & 0 & 40.4 \\
\hline 2. Culling of only clinically diseased cows & $4(6)$ & $7(6)$ & $15(6)$ & 40.4 \\
\hline 3. Culling 1 yr after first positive test & $63(6)$ & $151(7)$ & $239(7)$ & 41.6 \\
\hline 4. Culling 6 mo after first positive test & $72(6)$ & $182(7)$ & $323(7)$ & 41.3 \\
\hline 5. Culling $3 \mathrm{mo}$ after first positive test & $80(6)$ & $216(6)$ & $373(6)$ & 40.3 \\
\hline 8. Immediate culling of test positive cows & $90(6)$ & $240(6)$ & $403(6)$ & 39.7 \\
\hline 9. Improved management, no testing & $38(6)$ & $150(6)$ & $298(6)$ & 39.2 \\
\hline
\end{tabular}

${ }^{1}$ The replacement rate is listed for yr 20 only, because it varied negligibly over years.

${ }^{2}$ Mycobacterium avium ssp. paratuberculosis.

because it implied no losses related to culling. However, this strategy quickly turned out to be the least profitable of all because it had almost no prevalence-reducing effect. The rest of the paper will focus on the other strategies, all of which had some controlling effect on prevalence.

Except from strategy 2, culling of test-positive animals due to low milk yield (strategy 6) seemed to be the most favorable culling strategy economically in the first $7 \mathrm{yr}$ in herds with typical reproduction and in the first $10 \mathrm{yr}$ in herds with poor reproduction (Figures 3 and 4). In herds with poor reproduction, however, improved management without testing was more favorable than the culling strategies in the period 4 to $9 \mathrm{yr}$. Strategy 8 (immediate culling) was the most favorable strategy in the long term (10 to $20 \mathrm{yr}$ ). Most culling strategies implied losses of US $\$ 5$ to 55 /stall per year in the first 3 to $9 \mathrm{yr}$ compared with doing nothing to control MAP infection in the herd (Figures 3 and 4). These losses were compensated for by increased gross margin 6 to $19 \mathrm{yr}$ after initiation of the control strategies. In Tables 3 and 4 are listed the years of break-even where the initial costs were fully compensated by increased income (due to lower prevalence leading to a higher milk production). After this point, the total economic effect (cumulated by year) of introducing the culling strategy instead of doing nothing was positive. When comparing the economic effects in herds with and without reproduction problems, the culling strategies were much more costly and economically unfavorable in herds with reproduction problems. Strategy 6 (culling of test-positives due to low milk yield) was the only exception, with a maximum loss per year of US\$16/ stall and a break-even point in yr 10. For all other culling strategies, break-even did not occur until yr 14 to 19 (Tables 3 and 4).

Changes in milk price did not affect the order of the curves in Figures 3 and 4 . Increasing the milk price by $5 \%$ shifted all lines upward in parallel by US $\$ 1$ to $5 /$ stall per year (changing over years), and downward when milk price was reduced by $5 \%$.

The market price of pregnant heifers normally varies more than milk price and was shown in this study to have a larger effect when different culling strategies were

Table 6. In a herd with poor reproduction, the effects on milk yield of the 8 control strategies are listed as the milk yield/cow per year (kg of ECM) in strategies 2 to 9 minus that in strategy 1 (standard error of the difference in parentheses)

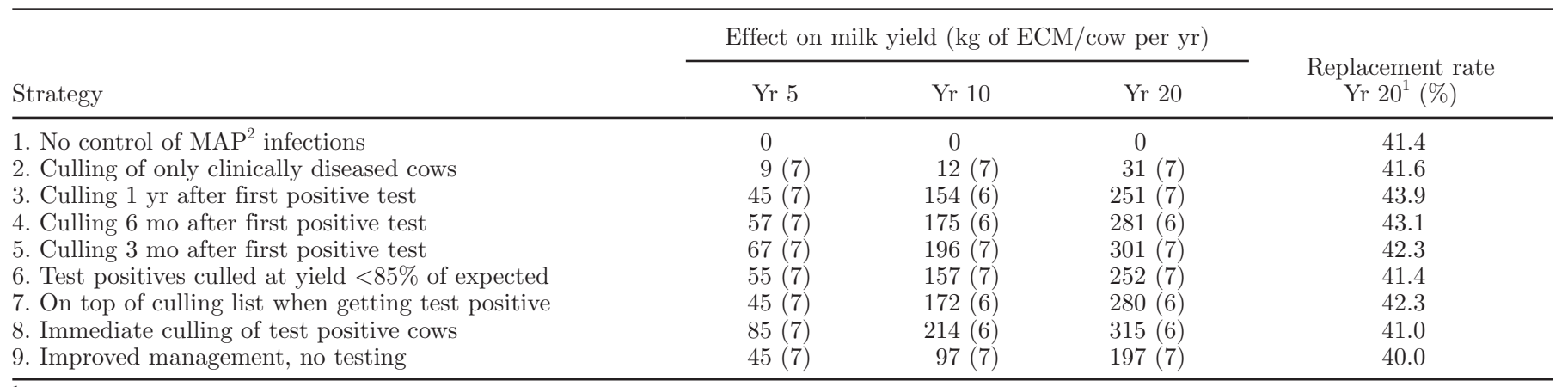

${ }^{1}$ The replacement rate is listed for yr 20 only, because it varied negligibly over years.

${ }^{2}$ Mycobacterium avium ssp. paratuberculosis. 


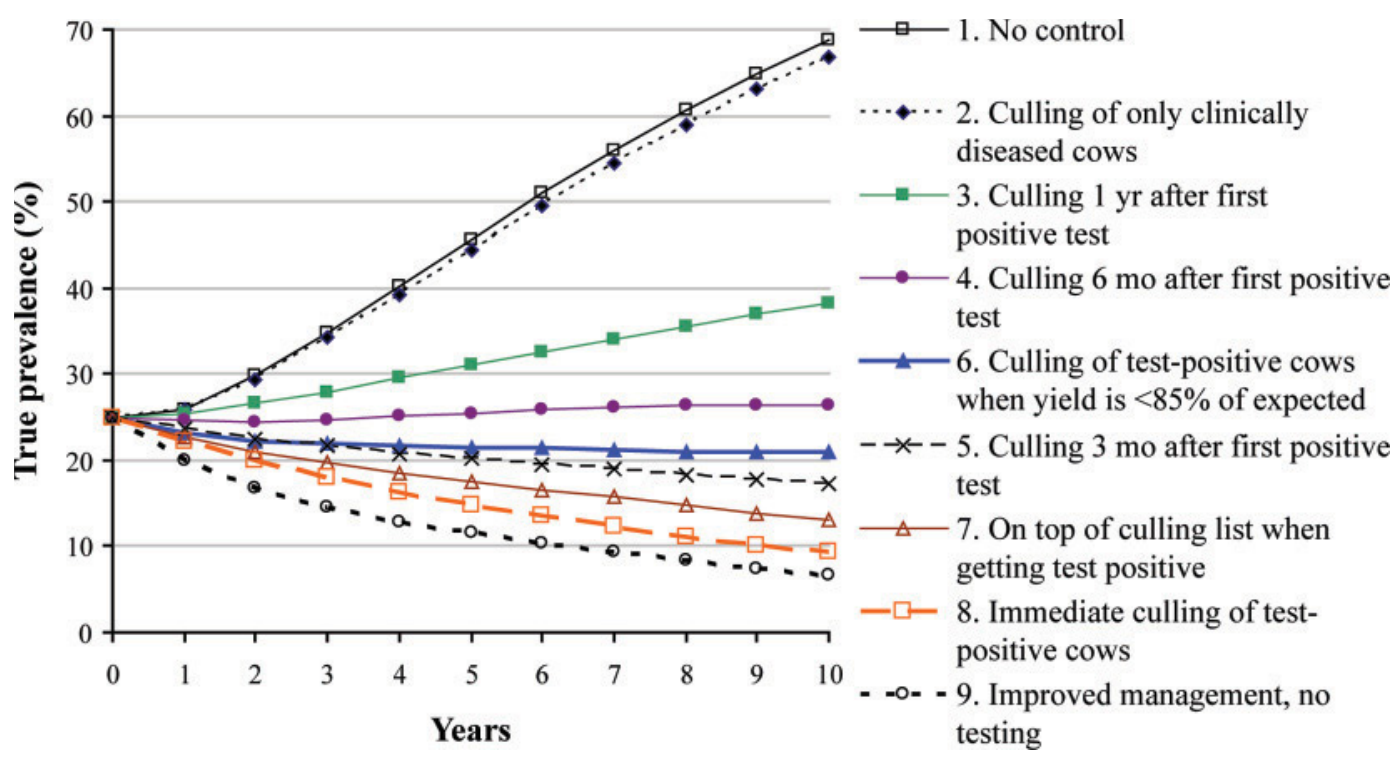

Figure 1. Simulated effects on true herd-prevalence of different culling strategies to control paratuberculosis in dairy herds with average reproduction management (heat detection rate 38\%). Culling strategies with decreasing time intervals from testing ELISA-positive the first time until culling (strategies 2-8) were compared with no control (strategy 1) and improved management of transmission routes (strategy 9). Color version available in the online PDF.

compared. An increase of this price by $20 \%$ resulted in (1) all culling strategies becoming less economically favorable, (2) a reduction in profit with faster culling after test-positivity (the curves in Figures 3 and 4), and (3) culling due to low milk production becoming the most profitable strategy for an even longer period (11 to 13 yr). A $20 \%$ lower price of replacement heifers resulted in the opposite situation: all culling strategies became more favorable and immediate culling after test-positivity became the most profitable culling strategy through all yr (0 to 20) in herds with typical reproduction and from yr 9 in herds with poor reproduction.

The profitability of strategy 9 (improved management) was almost unaffected by varying prices of replacement heifers. The level of hourly wages for carrying out the improved management, however, had a strong effect on the economy of this strategy. Increasing (decreasing) wages by $30 \%$ pushed the curve for strat-
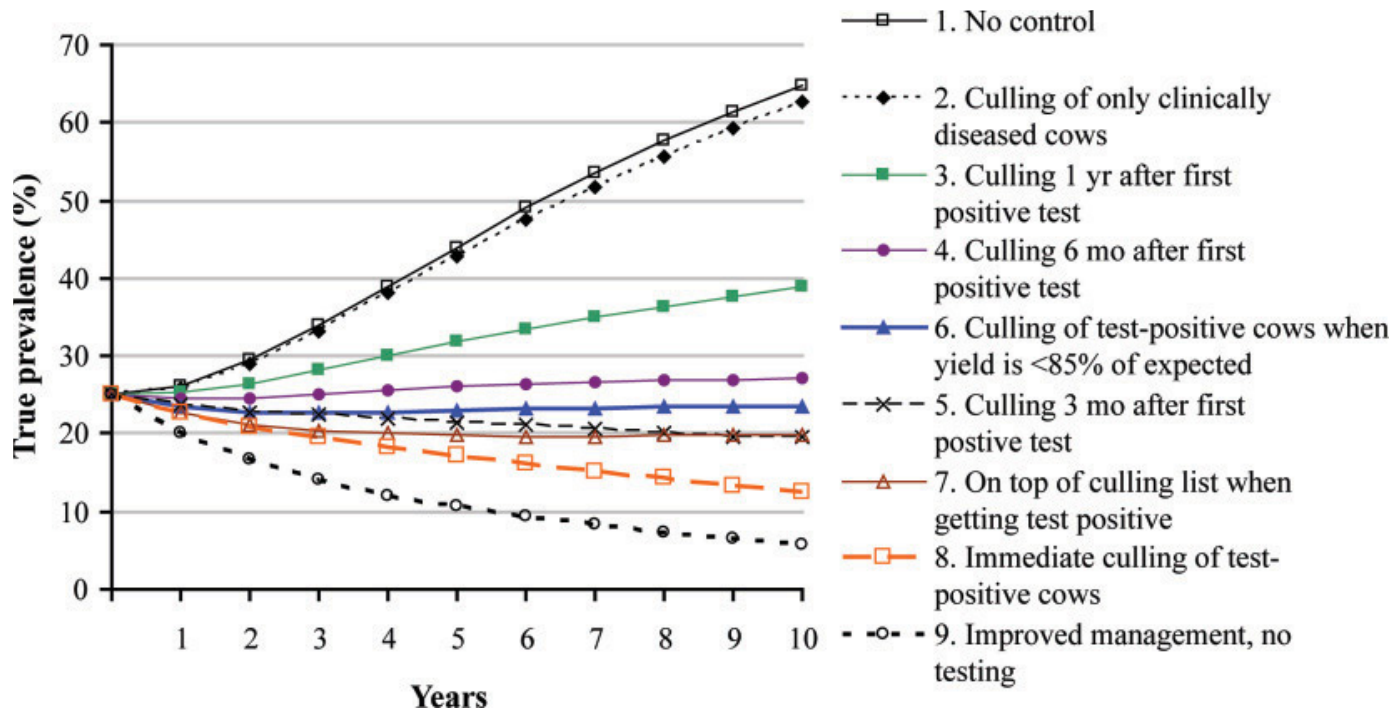

Figure 2. Simulated effects on true herd-prevalence of different culling strategies to control paratuberculosis in dairy herds with poor reproduction management (heat detection rate 28\%). Culling strategies with decreasing time-intervals from testing ELISA-positive the first time until culling (strategies 2-8) were compared with no control (strategy 1) and improved management of transmission routes (strategy 9). Color version available in the online PDF. 


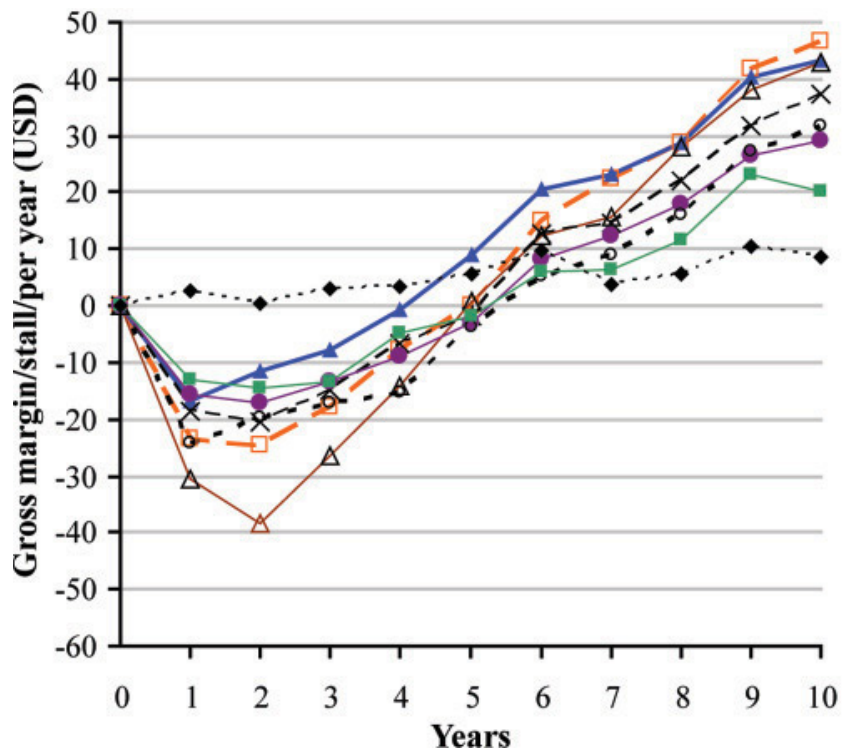

- -8 . Immediate culling of testpositive cows

$\longrightarrow 6$. Culling of test-positive cows when yield is $<85 \%$ of expected

$\triangle \quad 7$. On top of culling list when getting test positive

$--x-5$. Culling $3 \mathrm{mo}$ after first positive test

$\longrightarrow 4$. Culling $6 \mathrm{mo}$ after first positive test

- -o- - 9. Improved management, no testing

$=-3$. Culling $1 \mathrm{yr}$ after first positive test

$\cdots \bullet 2$. Culling of only clinically diseased cows

Figure 3. Simulated economic effects of culling strategies against paratuberculosis in dairy herds with average reproduction management (heat detection rate of 38\%) compared with no control of paratuberculosis [calculated as the difference in annual gross margin per stall (US\$) between no control and the respective culling strategies]. The curves illustrate what is gained or lost by introducing the culling strategies instead of doing nothing to control paratuberculosis. Color version available in the online PDF.

egy 9 downward (upward) by US $\$ 5$ to $6 /$ stall per year, making the profitability of this strategy very sensitive to hourly wages. We assumed that the improved management with regard to closing of transmission routes was applied to all calvings and calves (high hygiene of calving area, removal of calf, colostrum management, and hygienic calf stalling and feeding), and costs related to this strategy therefore depended only on the number of calving per year and the hourly wages.

We questioned whether the optimal strategy would change over time. A previous study found that the economic ranking of the different control strategies was

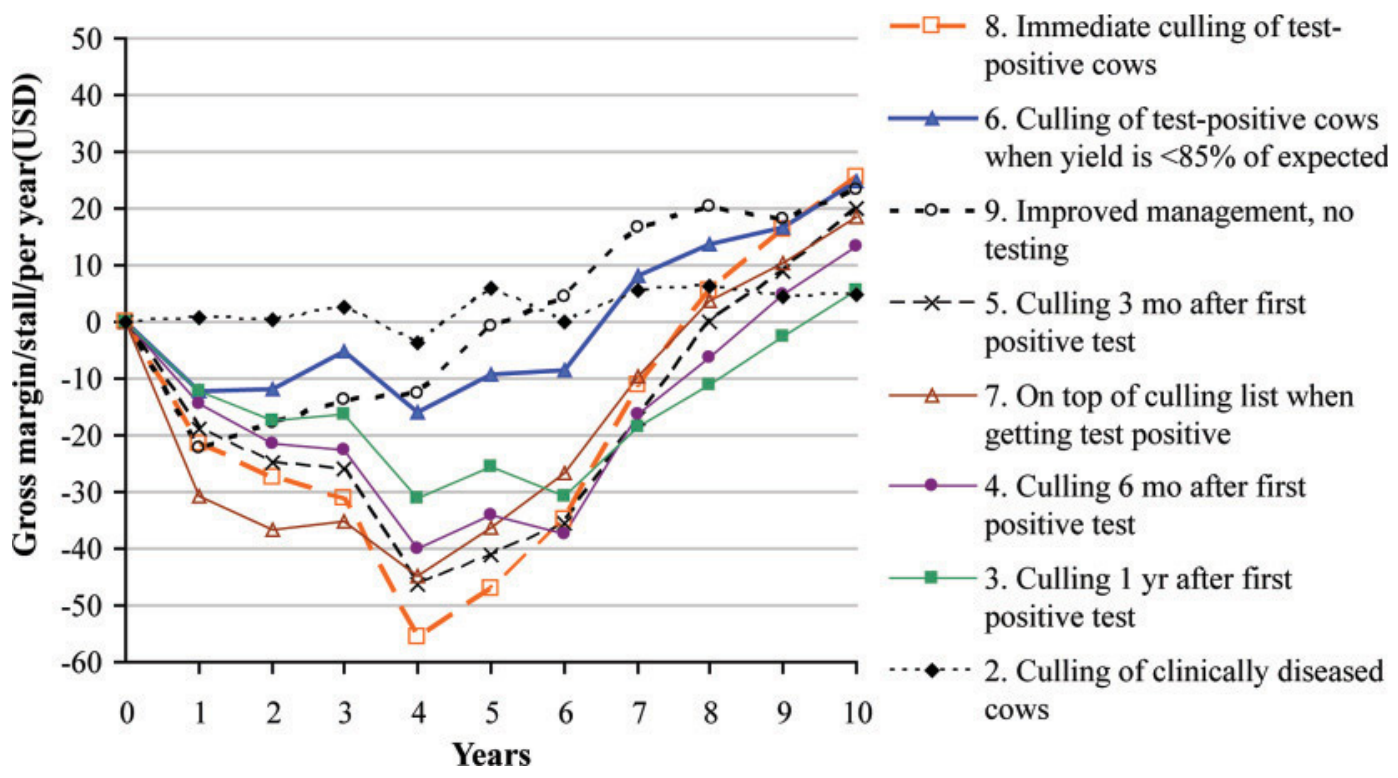

Figure 4. Simulated economic effects of culling strategies against paratuberculosis in dairy herds with poor reproduction management (heat detection rate of $28 \%$ ) compared with no control of paratuberculosis [calculated as the difference in annual gross margin per stall (US\$) between no control and the respective culling strategies]. The curves illustrate what is gained or lost by introducing the culling strategies instead of doing nothing to control paratuberculosis. Color version available in the online PDF. 
independent of prevalence (Kudahl et al., 2008). All present and earlier simulations, however, showed that in the first 3 to $4 \mathrm{yr}$, the most profitable strategy is always to do nothing and let the prevalence increase. Control strategies are an investment in the future, and if the control strategy is changed, the prevalence-reducing effect also changes. The optimal choice of strategy would probably be most affected by changing prices and other disease problems. In a herd with reproduction problems related to diseases, it might be advantageous to choose strategy 6 in the first years and then change to strategy 9, when the other disease problems have been handled.

\section{Prompt Culling Is Important}

With the current price set, the results suggested that in the long term (10 to $20 \mathrm{yr}$ ), the most cost-effective culling strategy is culling immediately after first positive test. Although it is slightly more expensive in the first year compared with culling based on a low milk yield criterion, it is more profitable in the long term because it reduces the prevalence, which is not achieved when using the milk yield criterion. The low milk yield criterion is still most profitable, however, in the first 7 to $10 \mathrm{yr}$, and optimistic farmers might choose this strategy while waiting for new knowledge on more costeffective control strategies.

Other simulation studies have compared the prevalence-reducing effect of different culling strategies. We found prompt culling of test-positive animals to be important in the case of poor management, and that supports findings by Lu et al. (2008) and earlier studies using PTB-Simherd (Kudahl et al., 2008). In the strategies simulated by Lu et al. (2008), all "high shedders" were culled immediately, regardless of management quality, whereas in the case of poor management, it was necessary to cull low shedders, too. If only high shedders were culled, faster MAP detection tests should be used with higher frequency and test sensitivity to obtain control of MAP (Lu et al., 2008). Previous simulations using PTB-Simherd also predicted that poor management necessitates fast culling of testpositive animals, whereas effective closure of infection routes made prompt culling of test-positive animals less important according to the prevalence-reducing effect (Kudahl et al., 2008).

The strategy with improved management simulated in the present study implied no testing and we assumed that general improvement of management takes $50 \mathrm{~min}$ extra per calving or calf in total for every calf. The costs for additional labor make this strategy quite expensive and very sensitive to increases in hourly wages. These costs can, however, be reduced considerably by focusing improved management on high-risk animals as identified by quarterly testing with ELISA (Kudahl et al. 2008).

The suggested culling strategies already imply quarterly testing, and information from these tests could, with little additional effort, be used for improving management for high-risk animals indicated by the tests. Such a combined strategy would lead to a more efficient reduction of prevalence with little additional cost (Kudahl et al., 2008). Especially in herds with reproduction problems, in which culling strategies alone are less effective, such a combined strategy might be attractive.

\section{Animals Testing Positive}

In the initial herd-state of our simulations, we had a true prevalence of $25 \%$, which resulted in, on average, 14 cows testing ELISA positive in the first year of simulation. In scenarios with delayed culling strategies, on average, 8 out of these 14 cows tested positive at second ELISA test 3 mo later, which indicates that they were at high risk of being infectious (Kudahl et al., 2008). The remaining group (i.e., on average, 6 cows $=43 \%$ ) thus included mainly low shedding and latently affected cows. Farmers will often be unwilling to cull these cows that are still performing well. Earlier simulations showed, however, that prevalence was not reduced, only stabilized, if cows were culled only after 2 positive tests instead of only one positive test (Kudahl et al., 2008). As an alternative strategy (simulated in Kudahl et al., 2008), farmers could supplement culling of cows with 2 positive tests with improved management of high-risk cows, which resulted in a much quicker and effective reduction of prevalence. Economically, such a strategy was more expensive in the first 3 to 4 yr than the culling strategies simulated in the present study because of the additional labor. However, it became even more profitable in a 10-yr period because prevalence was reduced much more rapidly (Kudahl et al., 2008).

\section{Effects of Poor Reproduction}

The results showed an interaction between culling strategies and herds with different reproduction efficiency. Our simulations predicted that poor reproduction made culling strategies less efficient in reducing prevalence and very costly in the first 6 to $10 \mathrm{yr}$ (except strategy 6), and that benefits from culling were smaller and occurred 6 to 9 yr later. In these herds, strategy 9 (improved management) and strategy 6 (culling of test-positive animals due to low milk yield) were the most favorable strategies economically.

Poor reproduction in a herd can be due to both low conception rate and low heat detection rate, and the reasons can be a mixture of health problems, nutrition, 
high milk yield, and management routines (Dobson et al., 2008; König et al., 2008; Gouttenoire et al., 2010;). We focused on the heat detection rate, which is influenced primarily by the methods and strategies used for heat detection (Firk et al., 2002). Although heat detection can be hindered by low intensity of estrus and lameness problems, heat detection rate is mainly influenced by the management of the farmer. In the present study, herds with reproduction problems were simulated with heat detection rates of $28 \%$. Average reproduction was simulated by a heat detection rate of $38 \%$ to represent the levels that are representative for a typical Danish herd (Ancker, 2008).

In herds with reproduction problems, fewer replacement animals are available. The decision to introduce a culling strategy of MAP-positive animals implies that the farmer has to consider adjustments of his or her general replacement strategy. Several options are possible: (1) prioritize culling of MAP-positive animals and keep cows with other health or fertility problems or low production for a longer period to avoid a reduction of herd size; (2) maintain the original strategy for voluntary culling. In case the farmer wants to keep his herd closed, or at least purchase as few animals as possible, the herd size will decrease, because additional animals are culled; and (3) maintain the original strategy for voluntary culling and purchase heifers or cows to retain herd size, which implies a risk of introducing new diseases. The effect on the individual herd can be any of these 3 options or a herd-specific combination of all 3 , depending on the replacement strategy of the farmer. In our simulated scenarios, we accepted a decrease in herd size to mimic a farmer who wants to minimize the purchase of heifers from other farms as a logical part of an eradication program. Purchase was not totally avoided, however, and over the years, an increasing number of animals was purchased. In yr 20, between 4 and 9 animals were purchased every year, depending on culling strategy. Without culling of PTB-positive animals, purchase was necessary to maintain herd size (6 animals in yr 20). In strategy 7 , MAP-positive animals were placed at the top of the culling list, and voluntary culling was thereby delayed. In this way, all consequences of introducing additional culling in a herd with reproduction problems were exemplified through the different simulated scenarios.

The economic figures are calculated in US dollars per stall per year and thereby reflect the marked effects of the decreasing herd size. To illustrate farmers who choose to retain herd size by purchasing more animals or keeping other animals on the culling list, all economic figures can be calculated as US dollars per cow per year. By doing this, the culling strategies become more economically favorable in herds with poor reproduction.

\section{Farmers' Goals}

In the interpretation and application of our simulated results, it is very important to define a relevant time horizon. The goals for control can vary: profit maximization (short and long term); eradication (prevalence $=0)$; control (reduction of prevalence); avoidance of spread (stabilization of prevalence); avoidance of clinical disease; or any combinations of these. Strategies 2 to 4 (culling of clinical diseased cows or culling 6 mo to $1 \mathrm{yr}$ after first positive test) would be satisfactory for a farmer who wants to avoid clinically diseased cows and who has a short economic timeframe (e.g., retirement within a few years). When the focus is optimizing the profit, the choice of strategy is influenced by the timeframe and reproduction management in the herd. Although this and earlier studies suggest prompt culling of MAP-infected cows for both epidemiological and economic reasons in the long term, farmers' decisions are also influenced by ethics and feelings and they are often reluctant to cull cows without clinical disease. The implementation of control strategies thus relies on good and informed communication between advisors and farmers to optimize decisions in the individual herd based on the current management and preferences of the farmer.

\section{CONCLUSIONS}

Our simulations predicted that all culling strategies would reduce gross margin during the first 3 to $6 \mathrm{yr}$. These losses were not compensated until 6 to $10 \mathrm{yr}$ after introduction of the culling strategy and, in the case of poor reproduction, after 10 to $19 \mathrm{yr}$. Poor reproduction made culling strategies less efficient in reducing prevalence and very costly the first 6 to $10 \mathrm{yr}$. Moreover, the benefit from culling was smaller and occurred 6 to $9 \mathrm{yr}$ later compared with herds with average reproduction. Culling of test-positive animals based on a milk yield criterion (below $85 \%$ of what was expected according to parity and lactation stage) seemed to be the most profitable strategy in the first $7 \mathrm{yr}$ in herds with typical reproduction and in the first $10 \mathrm{yr}$ in herds with poor reproduction. This strategy was not able to reduce prevalence, only stabilize it. Immediate culling after the first positive ELISA test was the most efficient culling strategy for reducing prevalence and the most profitable strategy in a 10- to 20-yr timeframe. Changes in milk price did not affect the ranking of the culling strategies, whereas varying prices of pregnant replacement heifers 
had a larger effect on the ranking. Decreasing the price of replacement heifers by $20 \%$ made immediate culling the most profitable strategy from yr 0 in herds with typical reproduction and from yr 9 in herds with poor reproduction. A $20 \%$ increase in heifer price prolonged the period in which culling from a milk yield criterion was the most favorable strategy by 3 to $4 \mathrm{yr}$.

\section{ACKNOWLEDGMENTS}

This study was financially supported by the Danish Directorate of Food, Fisheries and Agro Business (no. 3412-06-01550), the Danish Milk Levy Fund, and the Danish Cattle Levy fund.

\section{REFERENCES}

Ancker, M. L. 2008. Stor variation i reproduktionsresultaterne i Danmark. Kvæginfo - 1929a. Accessed Sep. 30, 2010. http://www. landbrugsinfo.dk/Diverse/KA/Sider/Stor_variation_i_reproduc tionsresultater1.aspx.

Behr, M. A., and V. Kapur. 2008. The evidence for Mycobacterium paratuberculosis in Crohn's disease. Curr. Opin. Gastroenterol. 24:17-21.

Chiodini, R. J., H. J. van Kruiningen, and R. S. Merkal. 1984. Ruminant paratuberculosis (Johne's disease): The current status and future prospects. Cornell Vet. 74:218-262.

Clausen, S. M., J. T. Sørensen, and A. R. Kristensen. 1995. Technical and economic effects of culling and reproduction strategies in dairy cattle herds estimated by stochastic simulations. Acta Agric. Scand. A Animal Sci. 45:64-73.

Dobson, H., S. L. Walker, M. J. Morris, J. E. Routly, and R. F. Smith. 2008. Why is it getting more difficult to successfully artificially inseminate dairy cows? Animal 2:1104-1111.

Fetrow, J., K. V. Nordlund, and H. D. Norman. 2006. Culling: Nomenclature, definitions and recommendations. J. Dairy Sci. 89:18961905.

Firk, R., E. Stamer, W. Junge, and J. Krieter. 2002. Automation of oestrus detection in dairy cows: A review. Livest. Prod. Sci. $75: 219-232$.

Gouttenoire, L., J. L. Fiorelli, J. M. Trommenschlager, X. Coquil, and S. Cournut. 2010. Understanding the reproductive performance of a dairy cattle herd by using both analytical and systemic approaches: A case study based on a system experiment. Animal $4: 827-841$.
Groenendaal, H., M. Nielen, A. W. Jalvingh, S. H. Horst, D. T. Galligan, and J. W. Hesselink. 2002. A simulation of Johne's disease control. Prev. Vet. Med. 54:225-245.

Kennedy, D., A. Holmström, K. Plym-Forshell, E. Vindel, and G. Suarez Fernandez. 2001. On-farm management of paratuberculosis (Johne's disease) in dairy herds. Bull. Int. Dairy Fed. 362:18-31.

Kennedy, D. J., and S. S. Nielsen. 2007. Report from the first IDF ParaTB Forum. Bull. Int. Dairy Fed. 410:3-7.

König, S., Y. M. Chang, U. U. v. Borstel, D. Gianola, and H. Simianer. 2008. Genetic and phenotypic relationships among milk urea nitrogen, fertility, and milk yield in Holstein cows. J. Dairy Sci. 91:4372-4382.

Kudahl, A. B., and S. S. Nielsen. 2009. Effect of paratuberculosis on slaughter weight and slaughter value of dairy cows. J. Dairy Sci 92:4340-4346.

Kudahl, A. B., S. S. Nielsen, and S. Østergaard. 2008. Economy, efficacy and feasibility of risk-based control program against paratuberculosis. J. Dairy Sci. 91:4599-4609.

Kudahl, A. B., S. Østergaard, J. T. Sørensen, and S. S. Nielsen. 2007. A stochastic model simulating paratuberculosis in a dairy herd. Prev. Vet. Med. 78:97-117.

Lu, Z., R. M. Mitchell, R. L. Smith, J. S. van Kessel, P. P. Chapagain, Y. H. Schukken, and Y. T. Gröhn. 2008. The importance of culling in Johne's disease control. J. Theor. Biol. 254:135-146.

Lu, Z., Y. H. Schukken, R. L. Smith, and Y. T. Gröhn. 2010. Stochastic simulations of a multi-group compartmental model for Johne's disease on US dairy herds with test-based culling interventions. J. Theor. Biol. 264:1190-1201.

Nielsen, S. S. 2008. Transitions in diagnostic tests used for detection of Mycobacterium avium ssp. paratuberculosis infection in cattle. Vet. Microbiol. 132:274-282.

Nielsen, S. S., H. Bjerre, and N. Toft. 2008. Colostrum and milk as risk factors for infection with Mycobacterium avium subspecies paratuberculosis in dairy herds. J. Dairy Sci. 91:4610-4615.

Nielsen, S. S., and N. Toft. 2009. A review of prevalences of paratuberculosis in farmed animals in Europe. Prev. Vet. Med. 88:1-14.

Østergaard, S., M. G. G. Chagunda, N. C. Friggens, T. W. Bennedsgaard, and I. C. Klaas. 2005. A stochastic model simulating pathogen-specific mastitis control in a dairy herd. J. Dairy Sci. 88:4243-4257.

Østergaard, S., J. T. Sørensen, and H. Houe. 2003. A stochastic model simulating milk fever in a dairy herd. Prev. Vet. Med. 58:125-143.

Ott, S. L., S. J. Wells, and B. A. Wagner. 1999. Herd-level economic losses associated with Johne's disease on US dairy operations. Prev. Vet. Med. 40:179-192.

Smith, R. L., Y. T. Gröhn, A. K. Pradhan, R. H. Whitlock, J. S. Van Kessel, J. M. Smith, D. R. Wolfgang, and Y. H. Schukken. 2009. A longitudinal study on the impact of Johne's disease status on milk production in individual cows. J. Dairy Sci. 92:2653-2661. 